\title{
Risk of musculoskeletal disorder among Taiwanese nurses cohort: a nationwide population-based study
}

Yueh-Chin Chung ${ }^{1,2}$, Chin-Tun Hung ${ }^{3}$, Shu-Fen Li ${ }^{3}$, Horng-Mo Lee ${ }^{4}$, Shyang-Guang Wang ${ }^{4}$, Shu-Chuan Chang ${ }^{2}$, Lee-Wen Pai ${ }^{2}$, Chien-Ning Huang ${ }^{1,5}$ and Jen-Hung Yang ${ }^{6^{*}}$

\begin{abstract}
Background: Musculoskeletal disorders (MSDs) represent the leading causes of occupational injuries among nursing staff. This population-based study was designed to assess the incidence and age-specific incidence of MSDs among a Taiwanese nurse cohort compared with non-nurses.

Description: Data from the Taiwan National Health Insurance Research Database were used to identify MSDs in the study population. A total of 3914 nurses with a diagnosis of MSD were included, together with 11,744 non-nurses as a comparison group. The comparison subjects were randomly selected at a ratio of 3:1 relative to the nurse population and were matched by gender and age. The incidence of MSDs was calculated for the study group, with nurse-to-reference risk ratios presented as odds ratios with 95\% confidence intervals (Cls). During the period 20042010, 3004 MSDs occurred among the nurses (76.24\%) and 7779 (65.79\%) in the non-nurses. The annual incidence of MSDs for the nurses increased from 28.35\% in 2006 to 33.65\% in 2010. The nurse-to-reference risk ratio was 1.27 (95\% Cl 1.19-1.35) in 2004 and 1.46 (1.37-1.55) in 2010. Herniation of intervertebral disc, lumbago, rotator cuff syndrome, medial epicondylitis, trigger finger and carpal tunnel syndrome were the most common problems.
\end{abstract}

Conclusions: Nurses are at higher risk of MSDs and the trend is increasing. Incorrect work-related posture/ movement, psychological issues and the rolling shift system may be the major causes of MSDs among nurses in Taiwan.

Keywords: Musculoskeletal disorders, Nurses, Low back pain, Epidemiology, Incidence

\section{Background}

Musculoskeletal disorders (MSDs) are inflammatory and degenerative conditions that affect the muscles, tendons, ligaments, joints or peripheral nerves, usually leading to ache, pain or discomfort [1,2]. MSDs are generally caused by repetitive manual labor, lifting heavy loads, overexertion, or working in an awkward posture. MSDs can have a serious impact on quality of life and may result in work restriction, absenteeism or even the need to change jobs [3-5].

The incidence of MSDs among healthcare workers is high, particularly in those who are involved in patient

\footnotetext{
* Correspondence: jh1000521@gmail.com

${ }^{6}$ College of Medicine, Tzu Chi University; Department of Dermatology,

Buddhist Tzu Chi General Hospital, Taiwan, No.701, Zhongyang Rd., Sec.3,

Hualien 97004, Taiwan

Full list of author information is available at the end of the article
}

handling [6-8]. Nurses routinely perform activities including lifting and moving patients, which are known risk factors for MSDs [2,9-11]. Low back pain (LBP) is the most common MSD in the nursing profession [12,13], accounting for $35-80 \%$ of the lifetime incidence [14-16].

MSDs seem to be prevalent among nurses, but observations in the literature based on questionnaires as measurement tools may not reflect the true situation throughout Taiwan. According to this report questionnaire is often influenced by information bias that should be minimized [17]. Clinical data on MSDs among nurses may better represent the importance of this issue, to obtain which a population-based longitudinal survey is required.

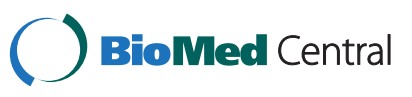

(c) 2013 Chung et al.; licensee BioMed Central Ltd. This is an Open Access article distributed under the terms of the Creative Commons Attribution License (http://creativecommons.org/licenses/by/2.0), which permits unrestricted use, distribution, and reproduction in any medium, provided the original work is properly cited. 
Taiwan's National Health Insurance Research Database (NHIRD) derives from the Taiwan National Health Insurance (NHI) program and is maintained by the Taiwan National Health Research Institute (NHRI), which updates data annually from the NHI program and classifies them for the NHIRD. In 2008, 22.89 million of Taiwan's 22.96 million people ( $99.7 \%$ of the island's population) were covered by the NHI program [18], a mandatory system that every person is required to join. In 2008, about 20.93 million persons claimed insurance, representing $91 \%$ of the insured population. More than 300 studies based on the NHIRD have been published in peer-reviewed journals. Using the NHIRD, the present study sought to determine the incidence and risk of MSDs in Taiwanese nurses and the particular MSDs for which they are most at risk.

\section{Construction and content Methods}

The Taiwanese National Health Insurance Bureau (NHIB) provides electronic data including patients' sex and birth date, the classification codes of diseases diagnosed, health services received, and the clinic or hospital code. The NHIB collects data from the NHI program and sorts it into data files each year, including registration files and original claim data for reimbursement. These data files are de-identified by scrambling the identification codes of both patients and medical facilities and are sent to the NHRI to form the NHIRD. The data used in this study were retrieved from a representative NHIRD cohort from January 2004 to December 2010. One million subjects were used for this longitudinal study. The sample size of 3914 nurses was selected randomly from the approximately 90,022 registered nurses in the NHI database. The nurses included in this study comprised 3861 women and 53 men. The reference population of 11,744 subjects was selected from 270,802 individuals whose occupation was not nursing and included both working and non-working subjects. Access to the NHIRD was approved by the NHRI Review Committee.

Cases of MSD were identified from the NHIRD for the years 2004 to 2010 using the 9th revision of the International Classification of Diseases, Clinical Modification
(ICD-9-CM), for both the registered nurses and the reference population. Abridged codes (A-codes) were converted into ICD-9-CM codes for data analysis. We excluded tumors (ICD-9-CM codes 170, 171 and 213) and trauma (injury or poisoning, ICD-9-CM codes 800-999). A MSD was defined as a diagnosis of either ICD-9-CM code 710739 or A-code 431-439. These MSDs include rotator cuff syndrome of the shoulder (ICD-9-CM 726.1), medial epicondylitis (ICD-9-CM 726.31), lateral epicondylitis (ICD-9CM 726.32), trigger finger (ICD-9-CM 727.03), radial styloid tenosynovitis (ICD-9-CM 727.04) and carpal tunnel syndrome (ICD-9-CM 354.0). Prolonged standing and lifting of heavy objects may contribute to LBP, so the incidences of nursing-related LBP, including lumbar spondylosis (ICD-9-CM 721.3), herniated intervertebral disc (HIVD) (ICD-9-CM 722.10), lumbago (ICD-9-CM 724.2) and backache (ICD-9-CM 724.5) were also compared between the two groups [19].

We first calculated the overall incidence of MSDs in the two study groups for the years 2004-2010. The annual incidence was the number of new cases of MSD divided by the size of the population at risk in each year. For example, the 2004 incidence was $1145 / 3914$, where 1145 is the number of new MSD cases in 2004 and 3914 was obtained by subtracting the number of MSD cases in 2003 from the population at risk in 2004. The sevenyear cumulative incidence was the number of new cases of MSDs divided by the size of the population at risk from 2004 to 2010. The annual incidence of MSDs was calculated for the study group, with the nurse-to-reference risk ratio presented as the odds ratio (OR) with its 95\% confidence interval (CI) [20]. The age-specific and site-specific incidences of MSDs during that period were also compared between the two groups.

\section{Results}

A total of 3914 nurses and three times this number of reference subjects $(11,744)$ were selected from the reimbursement claims database of the NHI of Taiwan. The gender distribution of the nurses $(98.64 \%$ women and $1.36 \%$ men) was comparable to that of the references, as was the age distribution. The seven-year cumulative

Table 1 Demographic data and seven-year cumulative incidence of musculoskeletal disorders (MSDs) in nurses and reference group

\begin{tabular}{llll}
\hline & & Nurses & Reference group \\
\hline$N$ & & 3914 & 11,744 \\
\hline Gender & Female & $3861(98.64 \%)$ & $11,585(98.64 \%)$ \\
\cline { 2 - 4 } & Male & $53(1.36 \%)$ & $159(1.36 \%)$ \\
\hline Age (years) & Female & $34.02 \pm 7.72$ & $34.05 \pm 7.73$ \\
\cline { 2 - 4 } & Male & $31.15 \pm 4.74$ & $31.15 \pm 4.71$ \\
\hline Seven-year cumulative incidence of MSDs $^{\text {a }}$ & & $3004(76.24 \%)$ & 7779 (65.79\%) \\
\hline
\end{tabular}

${ }^{a}$ Seven-year cumulative incidence is the number of new cases of MSD divided by the size of the population at risk from 2004 to 2010. 
Table 2 Annual incidence of musculoskeletal disorders (MSDs) in nurses and reference group, 2004-2010

\begin{tabular}{llllll}
\hline Year & \multicolumn{5}{c}{ Annual incidence ${ }^{\mathbf{a}}$ (\%) } \\
\hline $\mathbf{2 0 0 4}$ & Nurses & Reference group & Odds ratio & $\mathbf{9 5 \%}$ Confidence interval & \multicolumn{1}{c}{} \\
\hline $\mathbf{2 0 0 5}$ & 29.26 & 24.58 & 1.27 & $1.19-1.35$ & $<0.001$ \\
\hline $\mathbf{2 0 0 6}$ & 28.45 & 23.84 & 1.27 & $1.19-1.35$ & $<0.001$ \\
\hline $\mathbf{2 0 0 7}$ & 28.35 & 23.32 & 1.30 & $1.22-1.39$ & $<0.001$ \\
\hline $\mathbf{2 0 0 8}$ & 30.20 & 24.37 & 1.34 & $1.26-1.43$ & $<0.001$ \\
\hline $\mathbf{2 0 0 9}$ & 29.89 & 24.37 & 1.32 & $1.24-1.41$ & $<0.001$ \\
\hline $\mathbf{2 0 1 0}$ & 33.53 & 26.46 & 1.40 & $1.32-1.49$ & $<0.001$ \\
\hline
\end{tabular}

${ }^{a}$ Annual incidence is the number of new cases of MSD divided by the size of the population at risk in each year.

incidence of MSDs was higher among the nurses (76.24\%) than in the reference group (65.79\%) (Table 1$)$.

The annual incidences of MSDs during the period 2004-2010 were significantly higher among the nurses than the references (all $p<0.001$ ), with nurse-to-reference risk ratios ranging from 1.27 to 1.46 (Table 2). Notably, there was a trend of increasing incidence from 2005 (28.45\%) to 2010 (33.65\%). These data suggest that the nurses were more susceptible to MSDs than the nonnurse references, and that the annual incidence increased over a five-year period.

The age-specific incidence of MSDs ranged from $56.00 \%$ to $85.61 \%$ among the nurses. In both nurses and references, the age group with the highest incidence was the 20-24-year-olds and that with lowest was the $\geq$ 60 year-old group. The age-specific nurse-to-reference risk ratios for the annual incidences of MSDs for 20042010 ranged from 0.92 to 2.29 . In all age groups, the age-specific incidence of MSDs was consistently higher in the nurses than in the reference group (all $p<0.01$ ) (Table 3).

The incidences of MSDs in different parts of the body were investigated for the year 2010. Table 4 shows that the incidences of rotator cuff syndrome, medial and lateral epicondylitis, trigger finger, carpal tunnel syndrome, lumbar spondylosis, HIVD, lumbago and backache were significantly higher in the nurses than in the reference group (all $p<0.05$ ).

We next examined the age-specific incidence of LBP from 2004 to 2010; this was consistently higher among the nurses than the references $(p<0.01)$, with the exception of the 55-59-year-old group (Table 5). The nurse-to -reference OR was highest in 20-24-year-olds (OR, 1.60; $95 \% \mathrm{CI}, 2.67-2.97$ ) and those aged $\geq 60$ years (OR, 2.14; 95\% CI, 2.02-2.26). These data suggest that the oldest populations were the most vulnerable.

\section{Utility}

Musculoskeletal disorders (MSDs) represent the leading causes of occupational injuries among nurses. Our findings nurses are at higher risk of MSDs and the trend is increasing that considered when developing policies for the prevention of MSDs in the workplace, particularly with respect to occupation-associated injuries. Education program on prevention for MSDs and rolling shift system strategies may be helpful in reducing the incidence of MSDs.

Table 3 Average age-specific incidence a of musculoskeletal disorders (MSDs) among nurses and reference group, 2004-2010

\begin{tabular}{llllll}
\hline Age (years) & Nurses & Reference group & Odds ratio & 95\% Confidence interval & P \\
\hline $\mathbf{2 0 - 2 4}$ & 85.61 & 72.20 & 2.29 & $2.13-2.46$ & $<0.001$ \\
\hline $\mathbf{2 5 - 2 9}$ & 73.60 & 65.78 & 1.45 & $1.36-1.54$ & $<0.001$ \\
\hline $\mathbf{3 0 - 3 4}$ & 61.26 & 52.61 & 1.42 & $1.35-0.51$ & $<0.001$ \\
\hline $\mathbf{3 5 - 3 9}$ & 77.83 & 61.54 & 2.19 & $2.06-2.33$ & $<0.001$ \\
\hline $\mathbf{4 0 - 4 4}$ & 67.99 & 61.00 & 1.36 & $1.28-1.44$ & $<0.001$ \\
\hline $\mathbf{4 5 - 4 9}$ & 75.24 & 66.56 & 1.53 & $1.44-1.62$ & $<0.001$ \\
\hline $\mathbf{5 0 - 5 4}$ & 66.45 & 68.36 & 0.92 & $0.86-0.97$ & $<0.01$ \\
\hline $\mathbf{5 5 - 5 9}$ & 56.12 & 36.43 & 2.23 & $2.11-2.36$ & $<0.001$ \\
\hline $\mathbf{6 0}$ & 56.00 & 46.67 & 1.45 & $1.38-1.54$ & $<0.001$ \\
\hline
\end{tabular}

${ }^{\mathrm{a}}$ Incidence is the number of new cases of MSD divided by the size of the population at risk from 2004 to 2010. 
Table 4 Incidence and odds ratio (OR) for specific sites of musculoskeletal disorders (MSDs) in nurses and reference group in 2010

\begin{tabular}{|c|c|c|c|c|c|}
\hline \multirow{2}{*}{\multicolumn{2}{|c|}{ ICD-9-CM code ${ }^{a}$}} & \multicolumn{4}{|c|}{ Incidence ${ }^{\mathrm{b}}(\%)$} \\
\hline & & \multirow{2}{*}{$\begin{array}{l}\text { Nurses } \\
0.83\end{array}$} & \multirow{2}{*}{$\begin{array}{l}\text { Reference group } \\
0.53\end{array}$} & \multirow{2}{*}{$\begin{array}{l}\text { OR (95\% Confidence interval) } \\
4.33(2.51-7.47)\end{array}$} & \multirow{2}{*}{$\begin{array}{l}p \\
<0.001\end{array}$} \\
\hline 726.1 & Rotator cuff syndrome & & & & \\
\hline 726.31 & Medial epicondylitis & 0.25 & 0.09 & $3.37(1.49-7.63)$ & $<0.01$ \\
\hline 726.32 & Lateral epicondylitis & 0.58 & 0.39 & $2.16(1.23-3.79)$ & $<0.01$ \\
\hline 727.03 & Trigger finger & 0.48 & 0.26 & $2.63(1.45-4.75)$ & $<0.01$ \\
\hline 727.04 & Radial styloid tenosynovitis & 0.30 & 0.20 & $1.71(0.90-3.27)$ & 0.102 \\
\hline 354.0 & Carpal tunnel syndrome & 0.79 & 0.63 & $2.21(1.18-4.13)$ & $<0.05$ \\
\hline 721.3 & Lumbar spondylosis & 1.07 & 0.81 & $1.36(1.00-1.84)$ & $<0.05$ \\
\hline 722.10 & Herniated intervertebral disc & 1.45 & 0.64 & $2.48(1.82-3.38)$ & $<0.001$ \\
\hline 724.2 & Lumbago & 7.08 & 5.43 & $2.04(1.70-2.45)$ & $<0.001$ \\
\hline 724.5 & Backache & 4.34 & 3.14 & $1.68(1.40-2.01)$ & $<0.001$ \\
\hline
\end{tabular}

aCD-9-CM, 9th revision of the International Classification of Diseases, Clinical Modification.

${ }^{\mathrm{b}}$ Annual incidence is the number of new cases of MSD divided by the size of the population at risk in each year.

\section{Discussion}

A high incidence of MSDs among nurses has been demonstrated in numerous reports [21-24]. However, most of these surveys used questionnaires as measurement tools, which may not be compatible with the clinical diagnosis and evaluation of MSDs. The strength of this study is that most of the nurses in Taiwan were included for statistical analysis. The NHI in Taiwan is a mandatory universal health insurance program with more than 96\% coverage [18]. Because of the use of randomly selected reference subjects, the measurement of MSD incidence in the present study was reliable and similar to that obtained using the whole population as the denominator. Thus, information bias was substantially reduced. To our knowledge, no previous study has used nationwide health insurance data to investigate MSDs in nurses. However, this study is limited with respect to its generalizability because the incidence of MSDs was work related. In addition, not all nurses suffering MSDs seek medical attention that would be listed in the claim files. The database used in this study cannot provide information on an occupation-matched reference population; thus, another limitation of the present study is that we were unable to include both working and non-working populations as reference subjects. We can also assume that not every nurse with a MSD receives the same treatment as the non-nurse general public. Our statistical analysis was designed simply to indicate whether nurses have a higher incidence of MSDs than the general public.

This study demonstrated a higher incidence of MSDs among nurses. Our results agree with those published by Tinubu et al. [25], who reported a lifetime MSD incidence of $84.4 \%$ among nurses. Similar incidences of MSDs in nurses have been reported by other studies of various populations [6,24]. The seven-year cumulative incidence in Taiwan was $76.24 \%$, which is consistent with those previous reports. However, the incidence of MSDs among nurses was higher than that found in Chinese restaurant cooks, hotel-servers and community food service workers in Taiwan [26,27]. The relatively high incidence among our nurse cohort suggests that nurses work in a relatively high-risk environment for MSDs. The peak of age-specific MSD incidence in 2024-year-olds (85.61\%) warrants further discussion. Musculoskeletal pain has become a major complaint among young nurses and is increasingly occurring at a younger age $[28,29]$. The average age and seniority of nursing personnel are 26 and 4.73 years, respectively [30], and our findings should be considered when developing policies for the prevention of MSDs in the workplace, particularly with respect to occupation-associated injuries.

Table 5 Average age-specific incidence of low back pain (LBP) among nurses and reference group in 2004-2010

\begin{tabular}{llllll}
\hline $\begin{array}{l}\text { Age } \\
\text { (years) }\end{array}$ & Nurses & Reference group & $\begin{array}{l}\text { Odds } \\
\text { ratio }\end{array}$ & $\begin{array}{l}\mathbf{9 5 \%} \\
\text { Confidence } \\
\text { interval }\end{array}$ & $\boldsymbol{p}$ \\
\hline $\mathbf{2 0 - 2 4}$ & 60.35 & 48.79 & 1.60 & $2.67-2.97$ & $<0.001$ \\
\hline $\mathbf{2 5 - 2 9}$ & 56.09 & 48.34 & 1.36 & $1.29-1.44$ & $<0.001$ \\
\hline $\mathbf{3 0 - 3 4}$ & 52.30 & 41.83 & 1.52 & $1.44-1.61$ & $<0.001$ \\
\hline $\mathbf{3 5 - 3 9}$ & 57.52 & 45.03 & 1.65 & $1.56-1.75$ & $<0.001$ \\
\hline $\mathbf{4 0 - 4 4}$ & 57.17 & 49.00 & 1.39 & $1.31-1.47$ & $<0.001$ \\
\hline $\mathbf{4 5 - 4 9}$ & 59.85 & 57.76 & 1.09 & $1.03-1.15$ & $<0.01$ \\
\hline $\mathbf{5 0 - 5 4}$ & 60.08 & 58.43 & 1.07 & $1.01-1.13$ & $<0.05$ \\
\hline $\mathbf{5 5 - 5 9}$ & 50.21 & 49.23 & 1.04 & $0.98-1.10$ & 0.166 \\
\hline $\mathbf{6 0}$ & 56.00 & 37.33 & 2.14 & $2.02-2.26$ & $<0.001$ \\
\hline
\end{tabular}

Incidence is the number of new cases of LBP divided by the size of the population at risk from 2004 to 2010. 
Lumbago, backache and HIVD were the most common site-specific disorders. LBP is prevalent among nurses, nursing aides and nursing students [31]. The seven-year cumulative incidence of LBP was significantly higher in the nurse cohort (58.76\%) than in the reference group (49.02\%). This large difference may indicate which is the most vulnerable part of the body in nurses at work. The high incidence of lumbago may be a consequence of nurses spending long periods of time standing, and their lifting and moving of patients.

Chiou et al. [32] reported that the lifetime incidence of LBP is $77.9 \%$. Nursing tasks involving heavy physical labor and standing with the trunk in a bent or twisted position were the most common sources of back pain among nurses $[7,9,33]$. Overexertion of the back muscles can injure or tear ligaments in the back, which in turn leads to pain. Coping strategies include change of working technique, use of lifting equipment and avoiding strenuous tasks at work [15,34-36]. Educational programs on the prevention of or coping strategies for MSDs may be helpful in reducing their incidence [5,37].

In a questionnaire survey, Chen and Ting found that MSDs in nurses in Taiwan are primarily due to high workload and work pressure [38,39]. In other studies, Feng et al. and Nien found that $94.3 \%$ of Taiwanese nurses thought that MSDs may be caused by incorrect work-related posture/movement, insufficient rest or psychological conditions. They also considered the rolling shift system as a major cause of MSDs among Taiwanese nurses $[40,41]$.

\section{Conclusions}

The present study demonstrates that Taiwanese nurses are at higher risk of MSDs than the non-nurse population. The most critical cause for such MSDs was lack of training to be aware of the associated work-related situations. Education program may be helpful in reducing the incidence of MSDs.

\section{Availability and requirements}

In summary, the present study demonstrates that MSDs may represent a significant burden for nurses. The annual incidence of MSDs for the nurses was increased in the years 2006 to 2010. The age-specific incidences of MSDs of nurse were highest in the populations of 2024-year-old and those aged over 60. The Lumbago and back are the body parts most affected by MSDs, suggesting that education of ergonomics should be included in the nurse curriculum to reduce risks of MSDs in the future.

\footnotetext{
Abbreviations

MSD: Musculoskeletal Disorder; LBP: Low Back Pain; NHIRD: National Health Insurance Research Database; NHI: National Health Insurance; NHRI: National Health Research Institute; NHIB: National Health Insurance Bureau; ICD-9-
}

CM: 9th revision of the International Classification of Diseases, Clinical Modification; HIVD: Herniated Intervertebral Disc; OR: Odds Ratio;

Cl: Confidence Interval.

\section{Competing interests}

The authors declare that they have no competing interests.

\section{Authors' contributions}

YCC, CTH, SFL and HML participated in the conception and design of the study. YCC, SCC, HML and CNH performed the literature search and selection of studies. SFL, SGW, SCC, LWP and JHY extracted relevant data. CTH, HML and JHY participated in the analysis and interpretation of data and in the preparation and revision of the manuscript. All authors read and approved the final manuscript.

\section{Acknowledgements}

This study was supported by a grant from the Central Taiwan University of Science and Technology (CTU100-2). It was conducted partly using data from the National Health Insurance Research Database provided by the Bureau of National Health Insurance, Department of Health and managed by the National Health Research Institute. The interpretation and conclusions contained herein do not represent the opinions of the Bureau of National Health Insurance, the Department of Health or the National Health Research Institute.

\section{Author details}

'Institute of Medicine, Chung Shan Medical University, Taichung, Taiwan. ${ }^{2}$ Department of Nursing, Central Taiwan University of Science and Technology, Taichung, Taiwan. ${ }^{3}$ Department of Healthcare Administration, Central Taiwan University of Science and Technology, Taichung, Taiwan. ${ }^{4}$ Institute of Pharmaceutical Science and Technology; Department of Medical Laboratory Science and Biotechnology, Central Taiwan University of Science and Technology, Taichung, Taiwan. ${ }^{5}$ Department of Internal Medicine, Chung Shan Medical University Hospital, Taichung, Taiwan. ${ }^{6}$ College of Medicine, Tzu Chi University; Department of Dermatology, Buddhist Tzu Chi General Hospital, Taiwan, No.701, Zhongyang Rd., Sec.3, Hualien 97004, Taiwan.

Received: 30 August 2012 Accepted: 15 April 2013

Published: 23 April 2013

\section{References}

1. Smith DR, Kondo N, Tanaka E, Tanaka H, Hirasawa K, Yamagata Z: Musculoskeletal disorders among hospital nurses in rural Japan. Rural Remote Heal 2003, 3:241.

2. Long $\mathrm{MH}$, Johnston $\mathrm{V}$, Bogossian F: Work-related upper quadrant musculoskeletal disorders in midwives, nurses and physicians: a systematic review of risk factors and functional consequences. Appl Ergon 2012, 43:455-467.

3. Badley EM, Rasooly I, Webster GK: Relative importance of musculoskeletal disorders as a cause of chronic health problems, disability, and health care utilization: findings from the 1990 Ontario health survey. J Rheumatol 1994, 3:505-514.

4. Fronteira I, Ferrinho P: Do nurses have a different physical health profile? A systematic review of experimental and observational studies on nurses' physical health. J Clin Nurs 2011, 20:2404-2424.

5. King PM: Back injury prevention programs: a critical review of the literature. J Occup Rehabil 1993, 3:145-158.

6. Ando S, Ono Y, Shimaoka M, Hiruta S, Hattori Y, Hori F, Takeuchi Y: Associations of self estimated workloads with musculoskeletal symptoms among hospital nurses. Occup Environ Med 2006, 57:211.

7. Smedley J, Egger P, Cooper C, Coggon D: Manual handling activities and risk of low back pain in nurses. Occup Environ Med 1995, 52:160-163.

8. Waters TR, Rockefeller K: Safe patient handling for rehabilitation professionals. Rehabil Nurs 2010, 35:216-222.

9. Yip YB: A study of work stress, patient handling activities and the risk of low back pain among nurses in Hong Kong. J Adv Nurs 2001, 36:794-804.

10. Alexopoulos EC, Burdorf A, Kalokerinou A: Risk factors for musculoskeletal disorders among nursing personnel in Greek hospitals. Int Arch Occup Environ Health 2003, 76:289-294. 
11. Hui L, Ng G, Yeung S, Hui-Chan C: Evaluation of the physiological work demands and low back neuromuscular fatigue on nurses working in geriatric wards. Appl Ergon 2001, 32:479-483.

12. Stubbs DA, Buckle P, Hudson MP, Butler PE, Rivers PM: Back pain in the nursing profession, part I: epidemiology and pilot methodology. App/ Ergon 1983, 26:755-765.

13. Niedhammer I, Lert F, Marne MJ: Back pain and associated factors in French nurses. Int Arch Occup Environ Health 1994, 66:394-357.

14. Hignett S: Work-related back pain in nurses. J Adv Nurs 1996, 23:1238-1246.

15. Waddell G, Burton AK: Occupational health guidelines for the management of low back pain at work. Occup Med 2001, 51:124-135.

16. Sikiru L, Shmaila H: Prevalence and risk factors of low back pain among nurses in Africa: Nigerian and Ethiopian specialized hospitals survey study. East Afr J Public Health 2009, 6:22-25.

17. Fonseca Nda R, Fernandes Rde C: Factors related to musculoskeletal disorders in nursing workers. Rev Lat Am Enfermage 2010, 18:1076-1083.

18. Lu JF, Hsiao WC: Does universal health insurance make health care unaffordable? Lessons from Taiwan. Health Aff (Millwood) 2003, 22:77-88.

19. Churn-Shiouh G, Chang I-Shou W, Fe-Lin Y, Hui-Tzu HY-W, Cheng-Liang Chi S-Y, Chien K-ML, Liu M-Y, Wang H-P: Usage of the claim database of national health insurance programme for analysis of cisaprideerythromycin co-medication in Taiwan. Pharmacoepidemiol Drug Safe 2007, 16:86-95.

20. Davies HT, Crombie IK, Tavakoli M: When can odds ratios mislead? BMJ 1998, 316:989-991.

21. Shiue HS, Lu CW, Chen CJ, Shih TS, Wu SC, Yang CY, Yang YH, Wu TN: Musculoskeletal disorder among 52,261 Chinese restaurant cooks cohort: result from the national health insurance data. $J$ Occup Health 2008, 50:163-168.

22. Harber P, Billet E, Gutowski M, SooHoo K, Lew M, Roman A: Occupational low-back pain in hospital nurses. J Occup Med 1985, 27:518-524.

23. Brulin C, Goine $H$, Edlund C, Knutsson A: Prevalence of long-term sickleave among female home care personnel in northern Sweden. J Occup Rehabil 1998, 8:103-111.

24. Smith DR, Leggat PA: Musculoskeletal disorders in nursing. Aust Nurs $J$ 2003, 11:1-4.

25. Tinubu BMS, Mbada CE, Oyeyemi AL, Fabunmi A: Work-related musculoskeletal disorders among nurses in Ibadan. South-west Nigeria: a cross-sectional survey. Musculoskeletal Disord 2010, 11:12.

26. Chyuan JYA, Du CL, Yeh WY, Li CY: A cross-sectional study of musculoskeletal disorders in relation to work movement characteristics among hotel foodservice employees in Taiwan. Taiwan J Public Health 2002, 21:140-149.

27. Chyuan JYA, Ho JH, Sung FC: Risk factors associated with work-related musculoskeletal discomfort among commissary foodservice workers. Taiwan J Public Health 2005, 24:154-161.

28. Huang IC, Yang CH, Sung FC, Chen HF, Li CY: Incidence of ambulatory care visits among female nursing staff in Taiwan: a claim data-based retrospective cohort analysis. J Clin Nurs 2008, 18:1207-1216.

29. Choobineh A, Movahed M, Tabatabaie SH, Kumashirom M: Perceived demands and musculoskeletal disorders in operating room nurses of shiraz city hospitals. Ind Health 2010, 48:74-84.

30. Chiang CY: A study on factors affecting nursing turnover in Taiwan - trend analysis from 1999 to 2005. National Sun Yat-sen University. Institute of Human Resource Management: Master's thesis; 2006.

31. Mitchell T, O'Sullivan PB, Smith A, Burnett AF, Straker L, Thornton J, Rudd CJ: Biopsychosocial factors are associated with low back pain in female nursing students: a cross-sectional study. Int J Nurs Stud 2009, 46:678-688.

32. Chiou WK, Wong MK, Lee YH: Epidemiology of low back pain in Chinese nurses. Int J Nurs Stud 1994, 31:361-368.

33. Lusted MJ, Carrasco CL, Mandyk JA, Healey S: Self reported symptoms of the neck and upper limbs in nurses. Appl Ergon 1996, 27:381-387.

34. Silverstein B, Viikari-Jutura E, Kalat J: Use of a prevention index to identify industries at high risk for work-related musculoskeletal disorders of the neck, back and upper extremity in Washington state, 1990-1998. Am J Ind Med 2002, 41:149-169.

35. Lambert VA, Lambert CE: Nurses' workplace stressors and coping strategies. Indian J Palliat Care 2008, 14:38-44.

36. Linton SJ, Kamwendo K: Low back schools: a critical review. Phys Ther 1987, 67:1375-1383
37. Viikari-Juntura E: The scientific basis for making guidelines and standards to prevent work-related musculoskeletal disorders. Appl Ergon 1997, 40:1097-1117

38. Chen PQ: Occupational injuries of the musculoskeletal system. J Int Med Taiwan 1996, 7:55-63.

39. Ting JC: Factors associated with nurses' low back pain preventive behaviorsapply health belief model. National Taiwan Normal University, Institute of Health Promotion and Health Education: Master's thesis; 2002

40. Feng CK, Yang AZ, Lin GM: Prevalence and associated factors of musculoskeletal symptoms in central hospital of nurses. Hungkuang $J$ 2000, 36:105-130.

41. Nien CK, Ke DS: Low back pain and occupationally related risk factors among nurses. Chin J Occup Med 1996, 3:37-44.

doi:10.1186/1471-2474-14-144

Cite this article as: Chung et al:: Risk of musculoskeletal disorder among Taiwanese nurses cohort: a nationwide population-based study. BMC Musculoskeletal Disorders 2013 14:144.

\section{Submit your next manuscript to BioMed Central and take full advantage of:}

- Convenient online submission

- Thorough peer review

- No space constraints or color figure charges

- Immediate publication on acceptance

- Inclusion in PubMed, CAS, Scopus and Google Scholar

- Research which is freely available for redistribution 